\title{
A TEORIA AMBIENTALISTA DE FLORENCE NIGHTINGALE NO ENSINO DA ESCOLA DE ENFERMAGEM ANNA NERY (1962 - 1968)
}

The Environmental Theory by Florence Nightingale in The Teaching Of The Nursing School Anna Nery (1962 - 1968)

La teoría ambientalista de florence nightingale en la enseñanza de la escola de enfermagem anna nery (1962 - 1968)

Veronica Cristin do Nascimento Haddad ${ }^{1}$

Tânia Cristina Franco Santos²

\section{RESUMO}

Estudo histórico-social. Objetivos: caracterizar a Teoria Ambientalista de Florence Nightingale e analisar a aplicação dos conceitos dessa teoria no ensino da disciplina "fundamentos de enfermagem" na EEAN. Fontes: quarta edição do "Novo Manual de Técnica de Enfermagem" de Elvira de Felice Souza, livros, leis, teses, dissertações, trabalhos científicos. 0 Manual apresenta princípios para a boa execução da assistência de enfermagem, citando ações que proporcionam ao doente bem-estar físico, mental e espiritual. Estes princípios corroboram os pensamentos de Florence Nightingale que denotam a importância da implementação de uma assistência caracterizada por condições de recuperação, cura e reabilitação relacionadas com a qualidade do ambiente. Conclusão: constatação de que o ensino na época focalizava não somente o desenvolvimento das técnicas de enfermagem de forma correta, mas também a prática de ações que garantissem o cuidado holístico através de uma assistência pautada nos valores morais da sociedade e pelos princípios éticos da profissão.

Palavras-chave: História da Enfermagem. Teoria de Enfermagem. Educação em enfermagem.

\begin{abstract}
The present paper is a social historical study. Aims: to show the characteristics of Florence Nightingale's Environmentalist Theory and to analyze the application its concepts in teaching "fundamentos da enfermagem" at EEAN. Sources: "Novo Manual de Técnica de Enfermagem", $4^{\text {th }}$ edition, by Elvira de Felice Souza; books; laws; theses; dissertations; and scientific papers. The Manual provides principles for proper performance of the nursing care practice, by citing actions that give to the sick person physical, mental and spiritual well-being. These principles agree with Florence Nightingale's thoughts about the importance of the implementation of a nursing care characterized by the conditions of recovery, healing and rehabilitation that are related to the quality of the environment. Conclusion: the teaching practice at the time focused not only on the correct nursing techniques development, but also on the practice of actions that would ensure a holistic care through the assistance based on society's moral values tand ethical principles of the profession.
\end{abstract}

Keywords: History of Nursing. Nursing Theory. Education Nursing.

\section{Resumen}

Estudio histórico y social. Objetivos: Caracterizar la Teoría Ambientalista de Florence Nightingale y analizar la aplicación de sus conceptos en la enseñanza de la asignatura "Fundamentos de Enfermería" en EEAN. Fuentes: $4^{a}$ edición del "Nuevo Manual de Enfermería Técnica", de Elvira de Felice Souza, libros, leyes, tesis, disertaciones y trabajos científicos. El manual establece los principios para el buen desarrollo de los cuidados de enfermería, citando las acciones que le dan al paciente el bienestar físico, mental y espiritual. Estos principios están de acuerdo con el pensamiento de Florence Nightingale, que denota la importancia de implementar un servicio caracterizado por las condiciones de la recuperación, curación y rehabilitación relacionadas con la calidad del medio ambiente. Conclusión: la constatación de que la enseñanza de la época focalizaba no solamente el desarrollo de las técnicas de enfermería de manera correcta, sino también la práctica de acciones que garantizan la atención integral a través de la asistencia basada en los valores morales de la sociedad y los principios éticos de la profesión.

Palabras clave: Historia de la Enfermería. Teoría de Enfermería. Educación en Enfermería

\footnotetext{
'Bolsista de iniciação científica FAPERJ. Escola de Enfermagem Anna Nery/Universidade Federal do Rio de Janeiro. Acadêmica do $7^{\circ}$ período do curso de enfermagem e membro do NUPHEBRAS. Rio de Janeiro - RJ. Brasil. E-mail: veronicapibn@hotmail.com; ${ }^{2}$ Professor Associado. Pós-Doutorado em História da Enfermagem pela Escuela de Enfermería. Universidad de Valladolid. Doutorado em Enfermagem pela Escola de Enfermagem Anna Nery/UFRJ. Bolsista de Produtividade em Pesquisa do CNPq. Membro fundador do NUPHEBRAS. Escola de Enfermagem Anna Nery/Universidade Federal do Rio de Janeiro. Departamento Enfermagem Fundamental. Membro da $17^{a}$ Diretoria Colegiada do Núcleo de Pesquisa em História da Enfermagem Brasileira NUPHEBRAS. Rio de Janeiro - RJ. Brasil. E-mail: taniacristinafsc@terra.com.br
} 


\section{INTRODUÇÃO}

0 objeto deste estudo é investigar a influência da teoria ambientalista de Florence Nightingale no ensino da disciplina Fundamentos de Enfermagem na Escola de Enfermagem Anna Nery (doravante EEAN) no período de 1962 a 1968.

0 recorte temporal compreende o período de $1962-$ 1968. 0 marco inicial - 1962 - corresponde à mudança de denominação da disciplina "Arte de Enfermagem", nomeada assim desde a Lei 775/1949' que dispunha sobre o ensino de enfermagem no país, para "Fundamentos de enfermagem", mediante o Parecer $271 / 1962^{2}$ que estabeleceu o currículo mínimo para a formação do enfermeiro, que se seguiu à Lei de Diretrizes e Bases da Educação Nacional de 1961. A partir desse e de outros acontecimentos ocorreram diversas mudanças em decorrência do novo contexto de ensino em que a disciplina passa a se enquadrar.

Outras mudanças que a disciplina sofreu são verificadas no marco final - 1968 - e foram decorrentes da Reforma Universitária de 1968, a qual gerou novidades para o ramo estudantil, especificamente na disciplina uma redistribuição do conteúdo e, posteriormente, uma realocação da disciplina no plano de curso da escola. Esses fatos caracterizaram um novo contexto de ensino.

Florence Nightingale é considerada a fundadora da enfermagem moderna, e há relatos sobre os pontos principais da vida desta ilustre mulher:

Florence Nightingale (1820-1910) teve pais ingleses e nasceu durante uma viagem a Florença, Itália. Sua maior realização foi o estabelecimento do conceito da preparação formal para a prática de enfermagem; a profissão de enfermeiro, assim, teve início com sua promessa de cuidar dos doentes. Sua fama espalhou-se com rapidez após seu trabalho, e o de um grupo de mulheres dedicadas, de cuidar dos doentes, durante a Guerra da Criméia $[\ldots]^{3}$

Florence provocou uma revolução no conceito de enfermeira da época, vindo a formar o que hoje denominamos de Enfermagem Moderna. Nesse contexto, Florence proclamou uma identidade profissional singular e simbiótica em termos de rituais e simbologia, disciplina e poder. A administração de hospitais, a formação da enfermeira e a educação em serviço foram, para Florence, a preocupação primordial de todo o seu empreendimento na Enfermagem, de acordo com a sua mais difundida obra, o livro "Notas Sobre Enfermagem: 0 que é e o que não é", escrita em 1859, traduzida para o português em $1989 .{ }^{4}$

As crenças de Nightingale acerca da enfermagem constituem o fundamento básico sobre o qual se pratica a enfermagem atualmente. Suas conviç̧ões religiosas e a experiência como enfermeira do exército, durante a Guerra da Criméia, tiveram forte influência sobre seu método e crenças acerca do cuidado com os doentes. ${ }^{3}$

Tais crenças caracterizaram os pensamentos de Florence, a então conhecida "dama da lâmpada" por perambular durante a noite velando os soldados feridos da guerra; esses pensamentos se transformaram em um modelo a ser seguido pelas moças da época que se inspiraram na dedicação dela para também desenvolverem o cuidado a doentes. É o fato dessa propagação dos preceitos de Florence que institui um modelo de enfermeira que passou a ser seguido na época, com reflexos até os dias de hoje.

A visão de Florence objetivava priorizar o fornecimento de um ambiente estimulador do desenvolvimento da saúde para o paciente. Ela acreditava que isso faria um diferencial na recuperação dos doentes, e são esses preceitos que sustentam a Teoria Ambientalista.

Florence então passa a adotar conceitos que definem 0 que envolve a questão do ambiente, sendo esses vistos como componentes físico, social e psicológico os quais precisam ser entendidos como inter-relacionados, e não partes distintas, separadas ${ }^{3}$.

Os diversos trabalhos escritos de Florence falam acerca do provimento de fatores como: ventilação, ar e água limpos, limpeza e calor, de modo que o processo de reparação, instituído pela natureza, não seja impedido. Sendo assim, auxiliar os pacientes para que mantenham suas capacidades vitais, satisfazendo suas necessidades, é tido como meta da enfermagem; portanto, de acordo com Florence, a enfermagem é uma prática não curativa, na qual o paciente é colocado na melhor condição para a ação da natureza. ${ }^{4}$

Nightingale reconheceu que um ambiente negativo poderia causar estresse físico, daí afetando o clima emocional do paciente. Em consequência, foi dada ênfase em oferecer ao paciente uma variedade de atividades que mantivessem sua mente estimulada [...] o tédio era tido como causador de sofrimento. ${ }^{3}$

Com relação à Escola de Enfermagem Anna Nery, sabese que ela foi inaugurada em 19 de fevereiro de 1923, e esse fato demarca a transplantação, para o Brasil, de um modelo de enfermagem que agregava às características do tradicional modelo Nightingale outras características oriundas do processo de adaptação à sociedade americana, desde a década de 1870 . Isso porque uma missão de enfermeiras americanas, patrocinada pela Fundação Rockfeller, foi trazida ao Brasil, com o objetivo de promover as inovações requeridas pelo Departamento Nacional de Saúde Pública, consideradas necessárias à efetivação da reforma sanitária, liderada por Carlos Chagas, sanitarista 
renomado, então diretor do departamento. Por isso mesmo, o modelo de ensino de enfermagem implantado no Brasil foi denominado modelo anglo-americano de enfermagem. ${ }^{5,6}$

Quanto à Disciplina Fundamentos de Enfermagem, a qual fazia parte do primeiro período do ciclo de formação do curso o período preliminar -, esta era considerada base para o ensino das demais disciplinas do currículo. Seu conteúdo envolvia o ensino de técnicas relativas ao bem-estar do paciente, como banho no leito, o preparo de drogas e soluções, economia hospitalar, entre outros. ${ }^{7}$

Perante os fatos apresentados, o presente estudo se justifica por abordar a importância de uma das principais teorias de enfermagem e sua correlação com o ensino da prática da profissão. Para isso, o estudo aborda as principais características observadas visando propiciar maior conhecimento do modelo de ensino voltado para a assistência seguido na época. Além disso, pode-se considerar que esse estudo contribuirá para suprir lacunas relativas ao tema verificadas pela ausência de trabalhos científicos sobre o uso da teoria aplicada no ensino da prática de enfermagem em bases de dados.

Dessa maneira, ante a problemática apresentada, este estudo tem a finalidade de caracterizar a Teoria Ambientalista de Florence Nightingale e analisar a aplicação dos conceitos dessa teoria no ensino da disciplina "fundamentos de enfermagem" na EEAN, através do manual de técnicas de Elvira de Felice Souza, adotado como livro texto na época para a disciplina.

\section{CONTEXTO HISTÓRICO-POLÍTICO: SUBSÍDIO PARA O ENSINO}

A situação :social e econômica do Brasil sofreu várias mudanças decorrentes da Primeira Guerra Mundial. Uma dessas mudanças trouxe inovações para o ramo da saúde em decorrência da reforma sanitária, a qual gerou, entre outras coisas, a criação da primeira escola de enfermagem organizada e dirigida por enfermeiras, que também compunham a maior parte do grupo que lecionava. Para isso, veio para o Brasil uma missão de enfermeiras norte-americanas, liderada pela Sra. Ethel Parsons, ainda sob os auspícios da Fundação Rockefeller. ${ }^{8-10}$

Embora tenha sofrido diversas adaptações, o sistema Nightingale influenciou profundamente a enfermagem nos Estados Unidos, tendo as escolas de enfermagem norte-americanas surgido inspiradas nos princípios ditados por Florence. Consequentemente, o modelo anglo-americano implantado no país conservava princípios preconizados por Florence, tais como a divisão e a hierarquização no trabalho de enfermagem. ${ }^{11}$

0 panfleto que divulgou o curso da Escola de Enfermeiras, veiculado em 1922 e intitulado "A Enfermeira Moderna: apelo às moças brasileiras" sintetizava a ideia da nova categoria profissional, eminentemente feminina, com forte apelo patriótico e religioso, destacando o papel social da mulher. ${ }^{6}$

As candidatas ao curso de enfermagem da EEAN passavam pelo Concurso de Habilitação, uma espécie de exame vestibular, constituído por provas de conhecimentos gerais, e ainda por uma entrevista, etapa necessária desde o início do funcionamento da Escola, quando eram avaliados aspectos comportamentais e afetivos da candidata ao curso de enfermagem. A entrevista, etapa necessária também para o ingresso das alunas em outras escolas de enfermagem, constituía-se em uma atitude criteriosa das dirigentes da Escola, pois não bastava avaliar a competência intelectual da candidata, mas também seus traços de caráter e origem social. ${ }^{11}$

Após implementar seus planos, em 1931, a missão norte-americana de enfermeiras terminou e a direção da então Escola Ana Néri passou ao comando de uma enfermeira brasileira, Rachel Haddock Lobo. Porém, antes da saída da missão, a escola foi considerada como padrão oficial para efeito de equiparação e reconhecimento de outras escolas de enfermagem que viessem a ser criadas, com o propósito declarado de garantir um alto nível de formação profissional de enfermagem no Brasil. ${ }^{8}$

Até a Reforma Universitária, a opção pela enfermagem era justificada pelas alunas em termos de religiosidade, vocação, patriotismo, desejo de servir e de trabalhar para os ideais da eugenia e, em menor proporção, pelo desejo de independência econômica. Até então, as jovens de classe média tinham como opções carreiras como as de professora primária, vendedora e secretária. ${ }^{11}$

Eé nesse contexto de intensas mudanças que a EEAN adaptava as condições de ensino no âmbito da prática de enfermagem, sempre buscando guardar os preceitos da profissão, mas sem ferir os novos ideais que a sociedade imputava ao meio social, econômico, educacional e político.

\section{MATERIAIS E MÉTODOS}

Este trabalho trata-se de um estudo histórico-social que traz como fonte primária principal a $4^{a}$ edição do "Nôvo Manual de Técnica de Enfermagem", lançada em 1966, com autoria de Elvira de Felice Souza, a qual encontra-se na Biblioteca Setorial de Pós-Graduação em Enfermagem, no Pavilhão de Aulas da EEAN, localizada à Rua Afonso Cavalcanti, 275, no bairro Cidade Nova. 
Além disso, como fontes secundárias, foram apresentados leis sobre o ensino da prática da enfermagem, trabalhos científicos, tese de doutorado, dissertação de mestrado e livros relativos ao tema e ao contexto histórico da sociedade brasileira, sendo tais fontes citadas no decorrer deste artigo bem como detalhadas na seção de referências bibliográficas.

0 período da coleta de dados foi de junho a setembro de 2010. No que se refere aos aspectos éticos e legais, este estudo está vinculado ao projeto "A Enfermagem Brasileira e os Regimes Ditatoriais do Século XX" aprovado pelo Comitê de Ética em Pesquisa da EEAN/HESFA segundo a Resolução $n^{\circ}$ 196/96 do Conselho Nacional de Saúde, em 24 de março de 2009.

Os dados foram organizados, classificados e analisados com base em fontes extraídas de livros, dissertações e artigos sobre a temática em apreço.

\section{RESULTADOS E DISCUSSÃO}

\section{A Teoria Ambientalista de Florence Nightingale e 0 Cuidado de Enfermagem}

A participação de Florence na Guerra da Crimeia teve fundamental influência sobre o desenvolvimento dos pensamentos inovadores trazidos por ela para o contexto do cuidado oferecido a um doente. Ela passou a compreender o que era eficaz na reabilitação dos soldados feridos em combate ou vindos de cirurgias e o que prejudicava esse processo. Esses ideais fazem parte do contexto da prática de enfermagem vivenciado pelos profissionais que atuam hoje em dia. Isso significa que a verdade de Florence foi estabelecida e serve de parâmetro até os dias de hoje, sendo inquestionável a efetividade de seus feitos. ${ }^{12}$

0 princípio fundamental do legado de Florence para a prática da profissão é a questão do ambiente. Os ideais referentes a esse princípio foram fundamentados na Teoria Ambientalista e foram considerados primordiais para o sucesso do trabalho de Florence e suas aprendizes, sendo verificados na eficaz redução das mortes de soldados feridos por infecção e na recuperação de pacientes.

Florence introduziu uma visão de enfermagem não só de intervenção direta no doente, mas da mesma forma ampliou as funções para o meio ambiente, organizando os serviços de lavanderia, rouparia, cozinha, dietética, almoxarifado e limpeza, tendo o controle deste [ambiente hospitalar] por meio de observação e supervisão rigorosas: organizou a hierarquia do serviço e introduziu o rigor da disciplina na Enfermagem. ${ }^{13}$

Há quatro conceitos principais que refletem a visão de Florence trazendo significação à sua teoria; tais conceitos ${ }^{3}$ conferem um amplo espectro de mundo, no qual devemos contextualizar o profissional de enfermagem:

1. Homem ou indivíduo - possui poderes reparadores vitais para lidar com a doença;

2. Enfermagem - a meta é colocar o indivíduo na melhor condição à ação da natureza que se dá, basicamente, através do impacto sobre o ambiente;

3.Saúde/doença- o foco recai sobre o processo reparador de melhora;

4.Sociedade/ambiente - envolve aquelas condições externas que afetam a vida e o desenvolvimento da pessoa. 0 foco recai sobre a ventilação, o calor, os odores, os barulhos e a iluminação.

No item quatro é possível verificarmos o conceito básico mais característico dos trabalhos escritos de Nightingale: 0 ambiente. A definição de ambiente idealiza que ele é tudo o que cerca ou envolve os seres vivos ou as coisas; um lugar. ${ }^{14}$ Logo, 0 que Florence acreditava era que tudo que está à volta do sujeito influencia e determina as condições de saúde e recuperação dele, sendo isto de forma a beneficiar essas condições ou prejudicá-las.

0 cuidado de enfermagem deve então focalizar a importância da higiene ambiental, conceito básico mais característico de seus trabalhos. Para Florence, o ambiente é visto como todas as condições e influências externas que afetam a vida e o desenvolvimento de um organismo, sendo capaz de prevenir, suprimir ou contribuir para a doença ou morte. ${ }^{4}$

Isso significa dizer que o trabalho de Florence baseavase, principalmente, no oferecimento ao paciente de condições mínimas de recuperação, estando a ventilação, 0 ar, a água (limpos), a limpeza e calor como protagonistas do processo natural de recuperação o qual, sob essas condições, é facilitado e não impedido. A comunicação com o paciente também era vista por Florence como parte dos princípios do cuidado, e esta fornecia condições de avaliar o estado afetivo do paciente e obter as queixas dele. ${ }^{3}$

Mediante esses achados é preciso incitar nos dias de hoje a necessidade da acreditação desses ideais outrora implementados e verificados eficientes quando no cuidado prestado ao doente, os quais, associados às tecnologias existentes na atualidade, podem alcançar eficácia ainda maior, contribuindo para o crescimento técnico-científico da profissão.

\section{A Disciplina Fundamentos de Enfermagem e o Manual de Técnica}

"Manuais de técnica apresentam a descrição dos procedimentos a serem executados, passo a passo, e especificam também a relação do material a ser usado; com o tempo, acrescenta-se à descrição das técnicas a razão de ser de tais procedimentos, com a busca de fundamentação em outras áreas do conhecimento"? 
Essa questão trazida pelo estudo citado reflete a dinâmica da EEAN que usou e usa o conhecimento de diversas fontes para desenvolver o ensino. Na época, dispunha-se de um manual de técnicas de autoria de Elvira de Felice Souza o qual foi muito utilizado para contextualizar, dentro dos ideais nightingaleanos, o ensino da prática de enfermagem.

Esse manual de técnicas analisado nesse seguimento teve seu ideal estabelecido durante o curso de graduação da autora - Elvira de Felice Souza - e foi desenvolvido por ela posteriormente, pois ela acreditava que o ensino da prática de enfermagem necessitava de parâmetros a serem seguidos os quais a autora buscou inserir no livro.

Elvira De Felice Souza (EFS) formou-se enfermeira na hoje Escola de Enfermagem Anna Nery, da Universidade Federal do Rio de Janeiro (EEAN/ UFRJ). Como diplomada, construiu uma dedicada e extensa carreira docente, ministrou disciplinas de graduação e pós-graduação. Na EEAN, lecionou os Fundamentos da Enfermagem durante 27 anos, abrangendo mais de cinquenta turmas do curso de graduação. Foi diretora da Escola Anna Nery de 1971 a 1975 [...] Os cargos administrativos por ela ocupados na UFRJ incluem a chefia da Maternidade Escola, de 1947 a 1951; a vice-direção da EEAN, de 1967 a 1971; a direção da Escola, de 1971 a 1975 [...] No último ano do curso de enfermagem, em 1945, EFS iniciou a elaboração do futuro "Manual de Técnica de Enfermagem", com o propósito de oferecer às alunas um guia para a correta execução dos procedimentos de enfermagem. O livro foi pela primeira vez compilado e mimeografado em $1948 .^{15}$

Tal manual constituía-se, portanto, a quinta obra brasileira publicada sobre fundamentos de enfermagem, e, na EEAN, o livro da professora Elvira passa a ser o único guia de execução das técnicas pelas alunas à época. ${ }^{15}$

Elvira de Felice Souza constituía-se no modelo a ser seguido por sucessivas turmas de alunas, pelo fato de ter lecionado os fundamentos da enfermagem durante diversos $\operatorname{anos}(1946-1973){ }^{?}$

Elvira relata em seu livro diversos aspectos de sua visão que se cruzam com os princípios nightingaleanos. Um desses aspectos é verificado quando Elvira de Felice Souza relaciona as técnicas de enfermagem a outras ciências, como a psicologia, garantindo à enfermeira a responsabilidade de "estudar as predisposições do comportamento e das reações do paciente".

De maneira geral, o livro demonstra que a autora tinha um cuidado em tratar dos aspectos gerais que envolvem o cuidado de enfermagem antes mesmo de contemplar o ensino das técnicas de enfermagem propriamente ditas. Definições de enfermagem e seus princípios, condições gerais para 0 desenvolvimento do cuidado de enfermagem, relações da enfermagem com outras ciências, as implicações legais na prática de enfermagem, conceito de paciente e os princípios de atenção da enfermagem junto a ele, além de outros pontos observados são trazidos como pressupostos para a implementação das técnicas de enfermagem.

Fazendo uma inter-relação com os ideais de Florence, Elvira relata as condições gerais para a boa execução de enfermagem, sendo estas envolvidas no ramo da segurança, do conforto e da economia de tempo/esforço/material. Higiene, restrições quanto às correntes de ar, calor ou frio como possíveis causadores de danos ao paciente, o silêncio evitando irritabilidade ao doente, isto é, "proporcionar ao doente tudo que contribua para seu bem-estar físico, mental e espiritual" são os exemplos de atitudes citadas por Elvira que vão ao encontro dos pensamentos de Florence Nightingale.

A boa execução das técnicas, segundo a professora Elvira, garantia a eficiência do trabalho da enfermeira, evitando o desperdício de tempo e de energia com movimentos e de material hospitalar (economia de tempo, esforço e material); garantia o conforto do paciente; e principalmente, garantia a segurança do doente, minimizando o risco de contaminação e os possíveis acidentes. ${ }^{11}$

Entretanto, no final da década de 70 , ocorreu a mudança do principal campo de estágio da EEAN (Hospital Escola São Francisco de Assis) para o Hospital Universitário Clementino Fraga Filho (HUCFF), cuja organização e funcionamento atendiam a uma lógica própria. Além disso, a reforma curricular do curso de graduação teve como uma de suas consequências a eliminação da disciplina Fundamentos de Enfermagem. Estes e outros fatores determinaram uma diminuição progressiva da utilização do "Manual de Técnica de Enfermagem" por docentes e alunos. ${ }^{15}$

Sobre os fundamentos de enfermagem, acredita-se que este ensino contemple a base necessária para a aprendizagem de outras disciplinas da profissão, sendo, por isso, durante muitos anos ensinados na EEAN. ${ }^{16}$

Os principais pontos que caracterizam a disciplina ministrada na época são descritos a seguir:

Antes da Reforma Universitária de 1968, a disciplina Fundamentos de Enfermagem, introduzida pelo Parecer $n^{\circ}$ 271/1962, mantinha características semelhantes às da denominação anterior, Arte de Enfermagem, sendo ministrada no primeiro ano de formação acadêmica, concomitantemente com as disciplinas biomédicas, nos quatro primeiros meses da graduação, o chamado Período Preliminar. As alunas tinham as aulas práticas da disciplina na "Sala de Técnicas", 
um laboratório que servia como "reduto preferencial da formação inicial da candidata à carreira de enfermeira". A disciplina compreendia igualmente o ensino das seguintes matérias: Técnica; Economia Hospitalar; Ataduras; Drogas e Soluções. A professora Elvira De Felice (Souza pelo casamento), regente de cátedra desta disciplina desde 1952, era a referência máxima para as alunas, ao demonstrar os procedimentos técnicos com propriedade e segurança, além do domínio da destreza manual e a máxima observância dos detalhes. ${ }^{2,11}$

Há ainda o relato de que a disciplina Fundamentos de Enfermagem foi atingida diretamente pela Reforma Universitária de 1968, no que se refere à sua inserção curricular, aos seus conteúdos, quanto à inclusão da abordagem das ciências biológicas (anatomia, fisiologia e bioquímica), e à relação professor-aluno, com importantes repercussões para a formação do enfermeiro. A carga horária era maior do que todas as disciplinas lecionadas no período preliminar (primeiros seis meses). ${ }^{11}$

Um ano após a Reforma, a carga horária da disciplina diminuiu de 640 para 500 horas, chegando ao longo do período estudado, à carga horária de apenas 300 horas. Porém, há que se considerar que parte dos conteúdos de Fundamentos de Enfermagem passou a ser lecionado na disciplina Introdução à Ciência da Enfermagem (75 horas), por professoras da disciplina Fundamentos de Enfermagem. ${ }^{11}$

A disciplina Fundamentos de Enfermagem manteve as mesmas matérias lecionadas quando estava em vigência a nomenclatura anterior, "Arte de Enfermagem", ou seja, compreendia o ensino das matérias: Técnicas; Drogas e Soluções; Economia Hospitalar; e Ataduras. Todas as matérias eram voltadas para o cenário hospitalar, demonstrando que a enfermagem no período estava essencialmente voltada para a assistência curativa. [...] Mesmo assim, observa-se que a disciplina Fundamentos de Enfermagem conserva alguns preceitos de Florence Nightingale, como a manutenção de um ambiente favorável, no sentido de que a natureza possa agir sobre o organismo, no sentido de restaurar a saúde do paciente $[. . .]^{11}$

A organização do programa de "Técnica" segue praticamente a mesma divisão utilizada no livro "Manual de Técnica de Enfermagem", da professora Elvira de Felice Souza, responsável pela disciplina Fundamentos de Enfermagem na EEAN desde $1946 .^{12}$

Mudanças importantes ocorreram na organização do curso, ocorrendo, por isso:
A transferência dos Fundamentos de Enfermagem para o segundo ano do curso de graduação foi uma das principais rupturas na disciplina que se seguiu à Reforma Universitária/1968. Somente após a aprovação nas disciplinas do Ciclo Básico e na disciplina Introdução à Ciência da Enfermagem, e após a Recepção das Insígnias, os alunos finalmente chegavam à disciplina Fundamentos de Enfermagem, que, desde 1969, era lecionada no $2^{\circ}$ ano de curso. O adiamento do contato com os Fundamentos de Enfermagem, neste sentido, possibilitou a aquisição do saber relativo aos Princípios Científicos, no Ciclo Básico, e o contato com um novo saber, na disciplina Introdução à Ciência da Enfermagem, relativo às bases teóricas da Enfermagem, que iria instrumentalizar o aluno de graduação para receber, na disciplina Fundamentos de Enfermagem, o ensino do processo de enfermagem, pelas primeiras mestrandas em enfermagem do Brasil. ${ }^{12}$

\section{CONSIDERAÇÕES FINAIS}

Florence tornou-se conhecida pelos seus atos que trouxeram resultados inovadores no tratamento de doentes. Tais atos refletiam o que hoje são os ideais deixados por Florence, que no ínterim de suas teorias são vistos como elementos essenciais para a implementação da recuperação da saúde de doentes.

Diversos elementos da teoria de Florence foram instituídos no contexto do ensino da prática de enfermagem em alguns locais do mundo, não sendo diferente o uso dos princípios nightingaleanos na EEAN. Tais ideais de Florence iam sendo adaptados à realidade e às necessidades das sociedades, cabendo aos então profissionais de enfermagem avaliarem cada contexto de forma a estarem exercendo a profissão da forma mais adequada segundo os preceitos da época; isto incluía o desenvolvimento do ensino, não sendo diferente essa adaptação na sociedade brasileira.

0 ensino do cuidado de enfermagem saudável deveria trazer esses ideais que noutro tempo foram implementados de forma tão eficaz a alcançar o sucesso. Entretanto, esses ideais têm ficado esquecidos em nossa história, e, em geral, a qualidade deficitária de ensino e assistência tem recaído sobre fatores como falta de novas tecnologias, a correria do dia-a-dia, falta de tempo do profissional em implementar o cuidado, do estudante em aprender, entre outros.

Atualmente, o comprometimento psicológico, e físico também, tem alcançado profissionais desde o momento do aprendizado, contribuindo, de certa forma, para corromper o papel profissional. A implementação do cuidado tem fugido dos princípios nightingaleanos, os quais têm ficado 
esquecidos na teoria quando deveriam ser protagonistas da prática de enfermagem.

Desta forma, conclui-se que o ensino das técnicas de enfermagem tem em sua trajetória o intuito de transmitir ao estudante que o primordial no cuidado prestado ao paciente é não somente o desenvolvimento da técnica de forma correta, mas também a prática de ações que garantam ao paciente um tratamento digno e o respeito sugerido pelos valores morais da sociedade e pelos princípios éticos da profissão.

\section{REFERÊNCIAS}

1. Lei $n^{0} 775$, de 06 de agosto de 1949. Dispõe sobre o ensino de enfermagem no país e dá outras providências. Diário Oficial da República Federativa do Brasil, 13 ago 1949.

2. Conselho Federal de Educação- CFE. Parecer n 271, de 19 de setembro de 1962. Currículo do Curso de Enfermagem. Documenta. Brasília (DF) 1962, 10(12): 54-60.

3. George JB et al. Teorias de enfermagem: os fundamentos para a prática profissional. São Paulo: Artes Médicas; 1993.

4. Nightingale F. Notas sobre enfermagem: o que é e o que não é. Tradução de Amália Correa de Carvalho. São Paulo: Cortez; 1989.

5. Santos TCF, Lopes GT, Porto F, Fonte AS. Resistência à liderança norte-americana na formação da enfermeira brasileira (1934-1938). Rev Latino-am Enfermagem. 2008 jan/fev; 16(1): 130-35.

6. Santos TCF, Barreira IA. 0 poder simbólico da enfermagem norte-americana no ensino da enfermagem na capital do Brasil: 1928-1938. Rio de Janeiro: EEAN/UFRJ; 2002.

7. Maciel RM, Barreira IA, Baptista SS. 0 ensino dos fundamentos de enfermagem na Escola Anna Nery em meados do século XX. Rev Enferm UERJ. 2009 jul/set; 17(3):344-49.

8. Baptista SS. A luta por um espaço na Universidade: 0 caso da Escola de Enfermagem Anna Nery [tese]. Rio de Janeiro: Escola de Enfermagem Anna Nery, Universidade Federal do Rio de Janeiro; 1995.
9. Santos LAC. O pensamento sanitarista na Primeira República: uma ideologia de construção da nacionalidade. Rev Cienc Soc. 1985; 28(2); 193-210.

10. Santos LAC. A Fundação Rockefeller e o Estado Nacional: história e política de uma missão médica e sanitária no Brasil. Rev Bras Est Popul. 1989; 6(1), 105-10.

11. Lucena, ICD. Fundamentos de enfermagem na Escola de Enfermagem Anna Nery (1962-1978): rupturas e continuidades [dissertação]. Rio de Janeiro: Escola de Enfermagem Anna Nery, Universidade Federal do Rio de Janeiro; 2010.

12. Marx K.. A guerra anglo-francesa contra a Rússia. Tradução de Marineli F, Dutra L Projeto História, São Paulo [on-line] 2008 jun; 6: [aprox.13 telas]. Disponível em: http:// scholar.google.com.br/scholar?hl=ptBR\&as_sdt $=0,5 \& q=$ Marinelli+e+Dutra.

13. Formiga JMM, Germano RM. Por dentro da história: o ensino de administração em enfermagem. Rev Bras Enferm. 2005 mar/abr; 58(2): 222-26.

14. Ferreira ABH. Miniaurélio Século XXI: o minidicionário da língua portuguesa. 5ª Rio de Janeiro: Nova Fronteira; 2001.

15. Lucena ICD, Barreira IA, Baptista SS. Cinquentenário do "Manual de Técnica de Enfermagem" (1957-2007): contribuições na construção do saber de enfermagem. Esc Anna Nery. 2010 jan/mar; 14 (1): 13-18.

16. Coelho CP. A Escola de Enfermagem Anna Nery: sua história, nossas memórias. Rio de Janeiro: Cultura Médica; 1997. 